\title{
Kronika Katedry Nauk Historyczno-Prawnych i Komparatystyki Prawniczej (2014 r.)
}

\section{Publikacje}

Aktywność naukowa pracowników Katedry w 2014 r. przyniosła plon w postaci licznych publikacji krajowych i zagranicznych, spośród których wyróżnia się książka habilitacyjna Piotra Fiedorczyka Unifikacja i kodyfikacja prawa rodzinnego w Polsce (1945-1964). Wydana przez Uniwersytet w Białymstoku monografia posłużyła za podstawę wszczęcia postępowania habilitacyjnego P. Fiedorczyka. Jego publikacja New Solutions in Polish Adoption Law and Proceedings została zamieszczona w opracowaniu zbiorowym Parents and Children in a Narrowing World. Issues on Adoption (red. M. D. Panforti, Modena 2014). Kolejny artykuł P. Fiedorczyka - Simplification of debt collection in Poland - national and EU perspective ukazał się w pracy zbiorowej Simplification of debt collection in the EU, (red. V. Rijavec, T. Ivanc, T. Keresteš, Lubljana 2014). W pracy zbiorowej Obszczestwo i Prawo. Issliedowatielskije perspektivy (red. A. Kondiakow, Petersburg 2015) ukazała się publikacja Adama Czarnoty Prawo, pamiat i zabwienije: relugorowanije collectiwnoj pamiati kwazisudebnymi institucjami. Kolejny z artykułów Adama Czarnoty Human rights and transitional justice in post-communist Central-Eastern Europe został zamieszczony w książce Towards recognition of minority groups. Legal and communication strategies (red. M. Zirk-Sadowski, B. Wojciechowski, K. M. Cern, Ashgate, Farnham, UK, Burlington, USA 2014). Piotr Niczyporuk pełnił funkcję konsultanta naukowego oraz współpracował przy redagowaniu polskiego przekładu księgi dwudziestej piątej i dwudziestej szóstej Digestów Justyniańskich (red. T. Palmirski, Kraków 2014). Ponadto, na łamach wydawanego w Rosji periodyku naukowego „Drevnee Pravo” opublikował następujące artykuły:

- Pravovaja zaščita beremennoj ženščiny, „Drevnee Pravo” 2014, nr 1

- Gosudarstvennye i častnye bankiry v drevnem Rime, „Drevnee Pravo” 2014, nr 2.

Artykuł K. Szcygielskiego Latin Terminology as an Element of Legal Education in Poland ukazał się w wydawnictwie pokonferencyjnym Past Lessons and Future Challenges. The 5th International Scientific Conference of the University of Latvia (red. K. Torgans, J. Pleps, Riga 2014). W czasopiśmie "Legal Roots The International Journal of Roman Law, Legal History and Comparative Law" (2014, nr 3) Piotr Kołodko zamieścił artykuł The genesis of the quaestorship in the 
ancient Rome: some remarks. Na łamach wydawanego przez Europejski Instytut Socjologii Prawa w Oniati (Hiszpania) czasopisma "Sortuz. Onati Journal of Emerging Socio-Legal Studies" (2014, nr 1) Adam Czarnota opublikował artykuł Post-communist rule of law in postdemokratic Euroepan Union.

W krajowych periodykach naukowych najczęściej publikował Piotr Niczyporuk. W 2014 r. ukazały się następujące artykuły jego autorstwa:

- Bankierzy publiczni w źródłach prawa rzymskiego, „Zeszyty Prawnicze” 14.1 (2014);

- Zawarcie małżeństwa „liberorum procreandorum causa" w prawie rzymskim, „Zeszyty Prawnicze" 14.3 (2014);

- Bankierzy publiczni w starożytnym Rzymie, "Zeszyty Naukowe Uniwersytetu Rzeszowskiego", Seria Prawnicza, z. 82/2014 Prawo 14;

- Bankierzy u Plauta, "Zeszyty Naukowe Uniwersytetu Rzeszowskiego", Seria Prawnicza, z. 82/2014 Prawo 14;

- Bankierzy rzymscy u Liwiusza, "Studia Prawnicze KUL” 2014, nr 1;

- Bankierzy w "Żywotach cezarów” Swetoniusza, „Krytyka Prawa. Niezależne studia nad prawem" 2014, t. 6;

- Cudze chwalicie, swego nie znacie: odpowiedź na recenzje Tomasza Giaro, „Forum Prawnicze" 2014, nr 2.

Adam Czarnota publikował na łamach czasopisma „Prawo i Więź”, w którym zamieścił następujące artykuły:

- Krótki esej o czterech ważnych kwestiach: prawie tożsamości, pamięci i wspólnocie, "Prawo i Więźz" 2014, nr 1;

- UwB czy UpB albo o tym, że uniwersytet bez biblioteki to twór uniwersytetopodobny, „Prawo i Więź” 2014, nr 4;

- Czy intelektualna historia prawa jest potrzebna?, „Prawo i Więź” 2014, nr 4; W "Zeszytach Prawniczych" (2014, 14.3) ukazała się publikacja P. Kołodki Uwagi na temat odpowiedzialności "magistratus populi Romani" w świetle prawa prywatnego oraz prawa publicznego. Artykuł Marcina Łysko Polityczne uwarunkowania orzecznictwa karno-administracyjnego Polski Ludowej ukazał się na łamach "Studiów z Dziejów Państwa i Prawa Polskiego" (t. XVII, Kraków - Lublin - Łódź 2014). Na łamach „Archiwum Filozofii Prawa i Filozofii Społecznej” (2014, nr 1) Karol Kuźmicz zamieścił artykuł Dlaczego kooperatyzm Edwarda Abramowskiego może nie być utopia. W periodyku „Krytyka Prawa. Niezależne studia nad prawem" $(2014$, t. 6) ukazał się artykuł Mariusza Mohyluka Działalność literacka Wacława Makowskiego.

W pracach zbiorowych Adam Czarnota zamieścił następujące artykuły:

- Rule of law and functions and dysfunctions of judicial culture in Central-Eastern Europe: reflections after 25 years from breakthrough, [w:] Court culture: contemporary problems (red. A. Piszcz, Białystok 2014);

- On the beauty of confusion, or transitional justice and rule of law, [w:] Wielowymiarowość prawa (red. J. Czapska, M. Dudek, M. Stępień, Toruń 2014); 
- Republikańska koncepcja rządów prawa albo co historyk idei może dać filozofowi prawa [w:] Tendencje rozwojowe myśli politycznej i prawnej (red. M. Maciejewski, M. Marszał, M. Sadowskiego, Wrocław 2014).

W pracy zbiorowej War and peace: philosophical, political and legal aspects, t. 1. Cultural conditionings (red. A. Breczko, F. Lempa, Białystok 2013) zostały opublikowane artykuły:

- F. Lempy, Etica della pace nell'insegnamento dei padri della Chiesa nei primi secoli del cristianesimo;

- I. Grata, Etyczne uzasadnienie wojny i pokoju w kontekście prawa naturalnego;

- M. Mohyluka, Bierdiajewa rozważania o wojnie.

\section{Konferencje naukowe}

\section{Zagraniczne}

Ważnym aspektem aktywności naukowej pracowników Katedry był udział w krajowych i zagranicznych konferencjach. Dwukrotnie uczestnikiem konferencji zagranicznych był Piotr Fiedorczyk. Podczas konferencji Dimensions of Evidence in European Civil Procedure (Maribor 20-21 marca 2014 r.) wystąpił w dyskusji na sesji plenarnej jako polski National Reporter. Uczestniczył również w zorganizowanym w La Corunie (9-11 czerwca 2014 r.) przez International Academy for the Study of the Jurisprudence of the Family sympozjum Family Law and Religion. Wystąpił z referatem Polish Family Law as a Field of Cooperation between Church and State. Na przełomie kwietnia i maja 2014 r. Piotr Niczyporuk uczestniczył w II Seminario Eurasiatico di Diritto Romano, które odbyło sie w Stambule. Wystąpił z referatem Chirographum jako pierwowzór stosunków kredytowych (Chirographuт как первообраз кредитных отношений). Kolejny raz przebywał w Stambule na przełomie października i listopada 2014 r. w związku z udziałem w Balkan Countries and Turkey I. Law Congress. Oprócz przewodniczenia obradom sesji plenarnej, wygłosił referat Osservazioni a margine furtum nell'attività bancaria di deposito. Wraz z Piotrem Kołodko uczestniczył w sympozjum szkoleniowo-merytorycznym Fondamenti Romanistci del Diritto Privato Europeo, które odbyło się 28 kwietnia - 4 maja 2014 r. w Haskovie (Bułgaria). Podczas seminarium Piotr Niczyporuk wygłosił serię wykładów na temat Attività di banchieri nella Roma antica come un prototipo delle moderne operazioni bancarie, podczas gdy wykłady Piotra Kołodko dotyczyły problematyki Praefectus vigilum as a guardian of the public order in ancien Rome. Adam Czarnota pełnił funkcję organizatora oraz kierował panelem dyskusyjnym podczas warsztatów Transitional justice workshop, które odbywały się w dniach 20-22 listopada 2014 r. w birmańskim Yangoon. Wystąpił tam z referatem Principles of constitutional democracy. W międzynarodowej konferencji naukowej Jurisprudence and 
Culture: Past Lessons and Future Challenges (Ryga 10-11 listopad 2014 r.), uczestniczyli Krzysztof Szczygielski (referat Latin Terminology as an Element of Legal Education in Poland) i Mariusz Mohyluk (referat Zasada niezawistości sądownictwa w II Rzeczypospolitej). Podczas międzynarodowej konferencji naukowej Rodzinna Europa. Europejska myśl polityczna a wyzwania XXI wieku (Wilno, kwiecień 2014 r.) Karol Kuźmicz wystąpił z referatem $A$ zatem wracajmy do Kanta, czyli o wspótczesnym znaczeniu filozofii politycznej myśliciela z Królewca.

\section{Konferencje krajowe}

Spośród konferencji krajowych największym zainteresowaniem pracowników Katedry cieszył się XXV Ogólnopolski Zjazd Historyków Prawa Nauka i nauczanie prawa w przeszłości i wspótcześnie, który odbył się w Krakowie 22-25 września 2014 r. Uczestnicząc w obradach poszczególnych sekcji referaty wygłosili:

- P. Fiedorczyk, Komisja Konsultacyjno-Naukowa przy Ministrze Sprawiedliwości. Z dziejów stalinizacji nauki prawa;

- P. Kołodko, Institutiones Marcianusa podręcznikiem do nauki prawa karnego w okresie cesarstwa;

- K. Kuźmicz, System edukacyjny i wychowanie w utopiach społecznych - główne założenia;

- M. Łysko, Udział doktryny w pracach nad kodyfikacja prawa wykroczeń Polski Ludowej;

- M. Mohyluk, Bierdiajewa lekcja komunizmu;

- P. Niczyporuk, Nauka prawa rzymskiego w Akademii Wileńskiej;

- K. Szczygielski, Aleksander Mickiewicz jako romanista. Przyczynek do nauki i nauczania prawa rzymskiego w Cesarstwie Rosyjskim w XIX wieku.

Karol Kuźmicz brał udział w:

- ogólnopolskiej konferencji naukowej: Wspótczesne oblicza bezpieczeństwa (Białystok 9-10 maja 2014 r.), wystąpienie Wolność czy bezpieczeństwo? Wokót problematyki hierarchii wartości wspótczesnego państwa demokratycznego;

- międzyśrodowiskowej konferencji naukowej Znaczenie ideałów (Nałęczów 2-4 czerwca 2014 r.), wystąpienie Bogactwo ideowe myślenia utopijnego;

- międzyśrodowiskowej konferencji Znaczenie pacyfizmu i braterstwa w czasach liberalizmu ekonomicznego (Kuźnica na Helu 24-27 października 2014 r.), wystąpienie Antropologiczny i kosmologiczny wymiar ideału braterstwa;

- konferencji naukowej: Filozofia. Prawo. Życie (Białystok 11 grudnia 2014 r.), wystąpienie Życie w utopiach.

Krzysztof Szczygielski brał udział w 5th Annual Polish-Spanish Conference on Roman Law Modern Application of the Roman Law Rules (Olsztyn 23 maja 2014 r.). Wygłosił referat The principle ius civile vigilantibus scriptum est in the judicial decisions of the Constitutional Tribunal and the Supreme Court. 


\section{Inne formy aktywności zagranicznej}

W trakcie sympozjum w La Coruna w Hiszpanii w czerwcu 2014 r. Piotr Fiedorczyk został wybrany do Board of Directors stowarzyszenia International Academy for the Study of the Jurisprudence of the Family. Stowarzyszenie grupuje 50 członków z blisko 20 krajów. Z kolei podczas światowego kongresu International Society of the Family Law, który miał miejsce w Recife (Brazylia), Piotr Fiedorczyk został ponownie wybrany do Executive Committee stowarzyszenia na 3-letnią kadencję. Stowarzyszenie liczy ok. 200 członków z całego świata. Filip Cyuńczyk otrzymał półroczne stypendium naukowe Europejskiego Instytutu Socjologii Prawa w Oniati (Hiszpania).

Piotr Niczyporuk uczestniczył w realizowanym w latach 2013-2015 przez Instytutu Historii Rosyjskiej Akademii Nauk grancie «Исследование по истории развития системы римского и европейского государственного права» (Badania na temat historii rozwoju systemu rzymskiego i europejskiego prawa publicznego). W ramach realizacji grantu badawczego Prawo karno-administracyjne Polski Ludowej Marcin Łysko przeprowadził tygodniowe kwerendy w Max Planck Institut fur Auschlandischisches und Internationales Strafrecht we Freiburgu (Niemcy - styczeń 2014) oraz Narodni Knihovna Czeskiej Republiki w Pradze (maj 2014). Uczestnicząc w programie LLP Erasmus Piotr Niczyporuk i Mariusz Mohyluk odbyli praktykę w kancelarii adwokackiej w Rzymie w dniach 6-13 września 2014. Z kolei podczas pobytu na University of National and World Economy w Sofii, wygłosili wykłady na temat Roman Banking Law as its influence on the Roman banking system in Europe (P. Niczyporuk) oraz Echoes of the Soviet law in the legal literature of the Second Republic of Poland (M. Mohyluk).

\section{Sympozja naukowe}

W 2014 r. z inicjatywy Zakładu Prawa Rzymskiego na Wydziale Prawa UwB zostały zorganizowane dwa sympozja naukowe. Oprócz pracowników Katedry, uczestniczyli w nich romaniści reprezentujący warszawskie i krakowskie środowisko naukowe. 14 stycznia 2014 r. odbyło się seminarium Łatwiej wielbłądowi...: emfiteuza między ekonomiq ziemska, a niebiańska, podczas którego referat wprowadzający wygłosił dr hab. Jakub Urbanik (UW). 9 grudnia 2014 r. miało miejsce seminarium poświęcone nowemu przekładowi Digestów Justyniańskich. Referat wprowadzający wygłosił prof. Janusza Sondel (UJ). W roku akademickim 2014/2015 Adam Czarnota współkierował interdyscyplinarnym seminarium Twarze Sprawiedliwości. W ramach seminarium odbywały się cykliczne spotkania dyskusyjne na Wydziale Prawa oraz Wydziale Socjologiczno-Historycznym Uniwersytetu w Białymstoku. 